This article was downloaded by: [Kerr, Alexander]

On: 24 July 2009

Access details: Access Details: [subscription number 913393824]

Publisher Taylor \& Francis

Informa Ltd Registered in England and Wales Registered Number: 1072954 Registered office: Mortimer House, 37-41 Mortimer Street, London W1T 3JH, UK

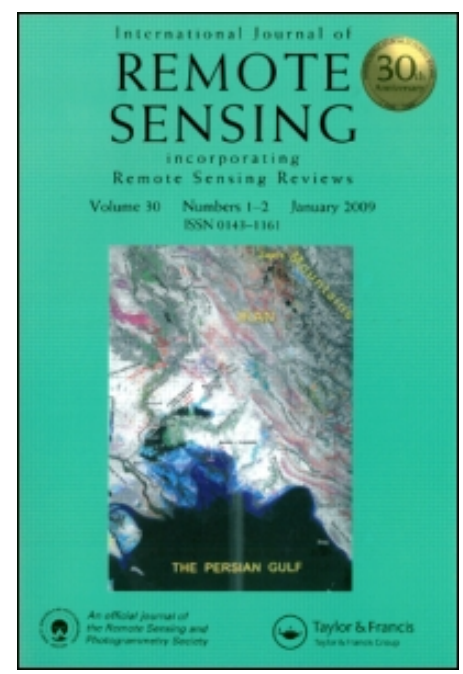

International Journal of Remote Sensing

Publication details, including instructions for authors and subscription information:

http://www.informaworld.com/smpp/title content=t713722504

\title{
Reply to 'Using remote sensing to assess the protective role of coastal woody vegetation against tsunami waves'
}

Alexander M. Kerr ab; Andrew H. Baird ${ }^{\mathrm{b}}$; Ravi S. Bhalla ${ }^{c}$; V. Srinivas ${ }^{\mathrm{c}}$

a Marine Laboratory, University of Guam, Mangilao, USA ${ }^{\mathrm{b}}$ ARC Centre of Excellence for Coral Reef Studies, James Cook University, Townsville, Australia ${ }^{\circ}$ Foundation for Ecological Research, Advocacy and Learning,

Vazhakulam, Puducherry 605 012, India

Online Publication Date: 01 January 2009

To cite this Article Kerr, Alexander M., Baird, Andrew H., Bhalla, Ravi S. and Srinivas, V.(2009)'Reply to 'Using remote sensing to assess the protective role of coastal woody vegetation against tsunami waves",International Journal of Remote Sensing,30:14,3817 $-3820$

To link to this Article: DOI: $10.1080 / 01431160903046711$

URL: http://dx.doi.org/10.1080/01431160903046711

\section{PLEASE SCROLL DOWN FOR ARTICLE}

Full terms and conditions of use: http://www.informaworld.com/terms-and-conditions-of-access.pdf

This article may be used for research, teaching and private study purposes. Any substantial or systematic reproduction, re-distribution, re-selling, loan or sub-licensing, systematic supply or distribution in any form to anyone is expressly forbidden.

The publisher does not give any warranty express or implied or make any representation that the contents will be complete or accurate or up to date. The accuracy of any instructions, formulae and drug doses should be independently verified with primary sources. The publisher shall not be liable for any loss, actions, claims, proceedings, demand or costs or damages whatsoever or howsoever caused arising directly or indirectly in connection with or arising out of the use of this material. 


\title{
Reply to 'Using remote sensing to assess the protective role of coastal woody vegetation against tsunami waves'
}

\author{
ALEXANDER M. KERR*†t, ANDREW H. BAIRD $\$$, RAVI S. BHALLA $\S$ and \\ V. SRINIVAS $\$$ \\ $†$ Marine Laboratory, University of Guam, Mangilao, GU 96923, USA \\ tARC Centre of Excellence for Coral Reef Studies, James Cook University, Townsville, \\ QLD 4811, Australia \\ §Foundation for Ecological Research, Advocacy and Learning, No. 27, 2nd Cross, \\ Appavou Nagar, Vazhakulam, Puducherry 605 012, India
}

(Received 8 April 2008; in final form 17 May 2009)

\begin{abstract}
In a recent paper in the International Journal of Remote Sensing, Olwig et al. [28 (2007) 3153-3169] present a comprehensive, geographic information system (GIS)-based description of the spatial distribution of damage from the 2004 Indian Ocean tsunami relative to coastal vegetation in Tamil Nadu, India, and conclude that '...mangrove forests and coastal shelterbelts provided protection from the [t]sunami.' In this comment, we demonstrate that the complex spatial pattern of damage makes their observational approach unable to substantiate this claim. Contrary to the authors' assertions, other factors known to affect tsunami inundation, such as elevation, near-shore bathymetry and patterns of land use, are shown to vary across their study site so as to create the appearance of a mitigating effect by vegetation on inundation and damage. We show that without explicitly quantifying and controlling for these confounding factors, it cannot be ascertained, even in principle, whether vegetation did ameliorate tsunami damage. We conclude with a call for analyses that can simultaneously assess the role of the discernibly manifold factors generating the pattern of inundation and damage of the 2004 tsunami.
\end{abstract}

\section{Introduction}

In the aftermath of the 2004 Indian Ocean tsunami, there is an urgent need to understand the processes responsible for the patterns of coastal inundation, damage and death. In particular, many studies have sought to assess the protective capacity of ecosystems, such as coral reefs and coastal forests, against tsunami attack. Results to date have been mixed, yet appear to diverge along methodological lines; anecdotal, observational or bivariate statistical accounts almost invariably support a role for reefs and forests, while multivariate statistical approaches, which consider potentially confounding factors, have failed to find an association. This disparity is hardly academic, as its resolution will guide the disbursement of reparation monies and inform policy aimed at minimizing loss of life and property in future events.

An important addition to this discussion is a recent paper by Olwig et al. (2007) in the International Journal of Remote Sensing. The authors present a picture of the spatial distribution of tsunami inundation. They then use these data to compare

*Corresponding author. Email: alexander.kerr@aya.yale.edu 
tsunami damage relative to woody vegetation and conclude that '....mangrove forests and coastal shelterbelts provided protection from the [t]sunami.' Unfortunately, this claim is based on the assumption of 'homogeneity' of other factors well known to affect coastal inundation and that covary with degree of vegetation. We argue below that the assumption of homogeneity view is false; indeed, the authors have misrepresented a number of sources in justifying this assumption, and we further demonstrate how their approach cannot, even in principle, evaluate such a claim. We conclude with a call for analyses that can simultaneously assess the role of the many factors generating the pattern of inundation and damage.

\section{Tsunami inundation as a multivariate issue}

First, Olwig et al. (2005) consider a single explanation for observations having several equally reasonable and, as we will show, correlated, but unconsidered alternatives. For example, they claim (p.3161) that three northern hamlets (T.S. Pettai, Vadakku Pichawaram and Therkku Pichawaram) incurred minimal damage because they were situated behind dense vegetation. However, in their figure 5, no area elsewhere sustained damage this far inland (to $3 \mathrm{~km}$ ), even when not fronted by vegetation. How then, exactly, does this observation support a mitigating role for vegetation?

Additionally, these three villages are more elevated than are other areas; for example, elevated necessarily more than the main river basin where, not surprisingly, damage extends farthest inland. These patterns immediately suggest that elevation played an important, but unquantified, role in the extent and pattern of damage. Thus, in the absence of a quantitative assessment that explicitly includes elevation as a variable, we cannot be reassured by their statement that: 'The topography is homogeneous, smooth and the maximum height recorded within $1000 \mathrm{~m}$ from the shoreline is about $2 \mathrm{~m}$ above mean sea level' (p. 3158). Indeed, the latter portion of this statement is remarkable, given that differences of a few metres in elevation have been shown to influence tsunami inundation (Kanoglu and Synolakis 1998, Peterson et al. 2005). In addition, several studies (Kathiresan and Rajendran 2005, Kerr et al. 2006, Vermaat and Thampanya 2006) report a strong, statistically significant influence due to elevation at the authors' own study location. Furthermore, the source of their stated topographic maximum of 'about $2 \mathrm{~m}$ ' is an atlas (Survey of India 1971) that only provides elevational data in 10-m contours. In a similar vein, there are other discrepancies between statements made in Olwig et al. (2007) and a previous presentation by many of the same authors (Danielsen et al. 2005) regarding these same data. Olwig et al. (2007) state that the site's bathymetry is 'homogeneous'. Yet Danielsen et al. (2005) conclude that 'there might be undetected sea bottom topographic phenomena, such as local depressions that could, even over short distances, influence the wave energy'. Both statements cannot be true. Similarly, Olwig et al. (2007) cite the Survey of India (1971) for elevational data, as mentioned above. However, in Danielsen et al. (2005) they reference Selvam et al. (2000), an atlas that we have examined that contains no topographic information.

In addition to the elevation and near-shore bathymetry discussed above, land-use patterns may also strongly affect tsunami inundation. Just south of the previously mentioned three inland villages, the authors, in their figure 5, map a large tract of damage in red, whose angular perimeter follows an abrupt change in land use along the same margin, as well as along a small river coursing its southern margin. This should constitute prima fascie evidence by the authors' own preferred approach, 
inspection of geographic information system (GIS)-generated imagery, of inundation mediated by a factor other than coastal forest. We note several other instances where damage also ends abruptly at obvious changes in land use.

In summary, given the likely, but unexamined, roles of elevation, bathymetry and patterns of land use, the issue surely warrants a quantitative and multivariate statistical approach. Wave run-up can be halted by other types of land cover, as well as being attenuated over the distances under discussion, given slopes of even a few metres. In situations displaying such a complicated pattern of response, we unfortunately have no recourse save to assess the probability of competing explanations in a formal analytical setting. Appeals to homogeneity and discussion of selected observations consistent with one hypothesis, a role for forest cover, however plausible a priori, are uninformative.

The authors finish their paper with a scatter plot (their figure 6) that they claim supports a protective role of vegetation. The data are derived from 100 parallel transects running $2 \mathrm{~km}$ inland from the shore on which they recorded the inland extent of coastal forest and the extent of tsunami damage. The pattern of the data in their figure suggests a negative correlation between forest width and damage. However, the latter variable has been measured in a most peculiar way; damage was only recorded on transects when it extended beyond the inland boundary of the coastal forest. Despite claims of extensive ground-truthing (pp. 3160, 3161, 3163), they did not indicate the extent of damage within the forested portions of transects recorded as having no damage. This probably accounts for the high number of transects ( 45 by our count) where no tsunami damage was recorded and would explain the apparent negative trend the authors ascribe to the data (p.3165). Thus, when damage is recorded, it in fact represents the sum of forest width plus the damage appearing beyond the forest boundary. Consequently, the 'length of damage' and 'forest width' are not independent measurements and we can therefore infer nothing from their graph. The correct approach would have been to measure inundation distance independent of forest width, and only then regress this against the width of forest. An analogous approach has been used by Bhalla (2007) and Chatenoux and Peduzzi (2007), and in both of these studies, forest did not explain the extent of tsunami damage.

Further problems with their figure 6 include the fact that the many data points may mislead on the strength of the apparent negative correlation (p.3165). The points are based on transects spaced only $200 \mathrm{~m}$ apart, raising the likelihood of extensive spatial autocorrelation in their data. Furthermore, transects, including those with zero forest cover, have been labelled as having dense or open vegetation. We wonder why areas having no forest cover can be categorized as having a type of forest, and why forest previously treated as 'relatively uniform' in Danielsen et al. (2006) is now heterogeneous.

\section{Conclusions}

We fully agree with Olwig et al. (2007) that, in general, an observational approach, as with satellite imagery, can be a valuable method for understanding many types of patterns and processes. However, when the factors under examination become numerous and their spatial distributions complex, an observational approach loses its power to provide robust answers. Consequently, the data in Olwig et al. (2007) do not permit any formal assessment of whether vegetation and tsunami damage are associated more than expected by chance. Thus, their work cannot, even in principle, 
address the role of vegetation in protecting the shorelines because the study has not also accounted for the assorted potential contributions of factors well known to modulate wave damage and covary with vegetation. Their attempt to circumvent this crucial issue by claiming to identify a study site where variables, other than forest cover, do not vary is demonstrably false, as indicated by other published studies, discussed above, that show a strong role for other factors in their study area.

\section{References}

Bhalla, R.S., 2007, Do bio-shields affect tsunami inundation? Current Science, 93, pp. 831-833.

Chatenoux, B. and Peduzzi, P., 2007, Impacts from the 2004 Indian Ocean tsunami: analysing the potential protecting role of environmental features. Natural Hazards, $\mathbf{4 0 ,}$ pp. 289-304.

Danielsen, F., Sorensen, M.K., Olwig, M.F., Selvam, V., Parish, F., Burgess, N.D., Hiraishi, T., Karunagaran, V.M., Rasmussen, M.S., Hansen, L.B., Quarto, A. and Suryadiputra, N., 2005, The Asian tsunami: a protective role for coastal vegetation. Science, $\mathbf{3 1 0}$, pp. 643.

Danielsen, F., Sorensen, M.K., Olwig, M.F., Selvam, V., Parish, F., Burgess, N.D., Topp-Jorgensen, E., Hiraishi, T., Karunagaran, V.M., Rasmussen, M.S., Hansen, L.B., Quarto, A. and Suryadiputra, N., 2006, Coastal vegetation and the Asian tsunami - Response. Science, 311, pp. 37-38.

KANOGlu, U. and SynOlakis, C.E., 1998, Long wave runup on piecewise linear topographies. Journal of Fluid Mechanics, 374, pp. 1-28.

KATHiRESAN, K. and RAJENDRAN, N., 2005, Coastal mangrove forests mitigated tsunami. Estuarine, Coastal and Shelf Science, 65, pp. 601-606.

Kerr, A.M., Baird, A.H. and CAmpbell, S.J., 2006, Comments on 'Coastal mangrove forests mitigated tsunami' by K. Kathiresan and N. Rajendran [Estuar. Coast. Shelf Sci. 65 (2005) 601-606]. Estuarine, Coastal and Shelf Science, 67, pp. 539-541.

Olwig, M.F., Sorensen, M.K., Rasmussen, M.S., Danielsen, F., Selvam, V., Hansen, L.B., Nyborg, L., VestergaArd, K.B., Parish, F. and KARUNAGARAN, V.M., 2007, Using remote sensing to assess the protective role of coastal woody vegetation against tsunami waves. International Journal of Remote Sensing, 28, pp. 3153-3169.

Peterson, C., Yeh, H., Chadha, R.K., Latha, G. and Katada, T., 2005, Flood elevation, inundation distance and flow competence of the 2004 Sumatra-Anadman tsunami, as recorded by tsunami deposits in thirteen shore-normal profiles from the Tamil Nadu coastline, India. ISET Journal of Earthquake Technology, 42, pp. 95-110.

Selvam, V., Navamuniyammal, M. and Gnanappazham, L., 2002, Atlas of Mangrove Wetlands of India, Part 1: Tamil Nadu (Chennai, India: M. S. Swaminathan Research Foundation).

Survey OF InDIA, 1971, Topsheet No. 58M/15 (Dehradun: Government of India).

Vermati, J.E. and Thampanya, U., 2006, Mangroves mitigate tsunami damage: a further response. Estuarine, Coastal and Shelf Science, 69, pp. 1-3. 